Revista Destaques Acadêmicos, Lajeado, v. 8, n. 4, 2016. ISSN 2176-3070 DOI: http://dx.doi.org/10.22410/issn.2176-3070.v8i4a2016.1229 www.univates.br/revistas

\title{
A UTILIZAÇÃO DE APLICATIVOS DA COMPUTAÇÃO EM NUVEM NO ENSINO SUPERIOR
}

\author{
Lucas Horn Körbes ${ }^{1}$, Maria Claude Schorr Wildner ${ }^{2}$
}

Resumo: O presente artigo constitui-se na identificação da percepção dos docentes e discentes de uma instituição de Ensino Superior, em relação ao uso do cloud computing, computação em nuvem, no ensino. Com isso, pode-se verificar como os docentes e discentes veem a aplicação dessa tecnologia, se têm dificuldades no manuseio e quais os benefícios obtidos. Para tanto, tornou-se fundamental uma abordagem sobre o avanço da tecnologia da informação, conceitos de cloud computing e sua aplicação no ensino, entre outros. O método para levantamento de dados foi uma pesquisa exploratória de caráter qualitativo e quantitativo, através de um questionário estrutural, análise documental e pesquisa bibliográfica. Após o levantamento teórico e a análise do ambiente, foram apresentadas as conclusões para aperfeiçoar o uso da tecnologia.

Palavras-chave: Tecnologia da informação. Cloud Computing. Ensino Superior.

\section{INTRODUÇÃO}

A capacidade de adaptação às novas tecnologias e o fenômeno da globalização criam uma forte ligação entre a Tecnologia da Informação (TI) e o processo de mudança organizacional. Os avanços tecnológicos vêm forçando as organizações a se reinventarem para seguirem competitivas perante o mercado, constituindo uma forma de sobrevivência. A TI vem auxiliando e proporcionando mecanismos na análise e implantação das mudanças organizacionais.

Um dos fatores que mais vem impulsionando o fenômeno da globalização é a Internet. Com ela é possível comunicar-se, além de obter informações de qualquer parte do mundo. Tornou possível interligar pessoas, empresas e criar um mundo totalmente ligado.

Com o objetivo de fornecer recurso de processamento e armazenamento fora das estruturas organizacionais, surge o termo cloud computing, computação

1 Formando em Administração - LFE Análise de Sistemas no Centro Universitário UNIVATES.

2 Mestra em Ensino de Ciências Exatas UNIVATES. 
em nuvem. Grande parte da capacidade de computação das grandes empresas está ociosa, havendo muita capacidade a ser oferecida no mercado, fazendo com que o cloud computing seja a evolução natural da TI e a maneira para aprimorar a capacidade de uso da computação no mundo.

Computação em nuvem substitui ativos de TI que precisam ser gerenciados localmente por funcionalidades e serviços a serem utilizados de forma remota, de acordo com a necessidade, podendo ser aumentada em momentos de pico ou diminuída em momentos ociosos, pagando, assim, somente pelo que realmente é usado.

A Figura 1 demonstra uma visão geral da computação em nuvem:

Figura 1 - Visão geral da computação em nuvem

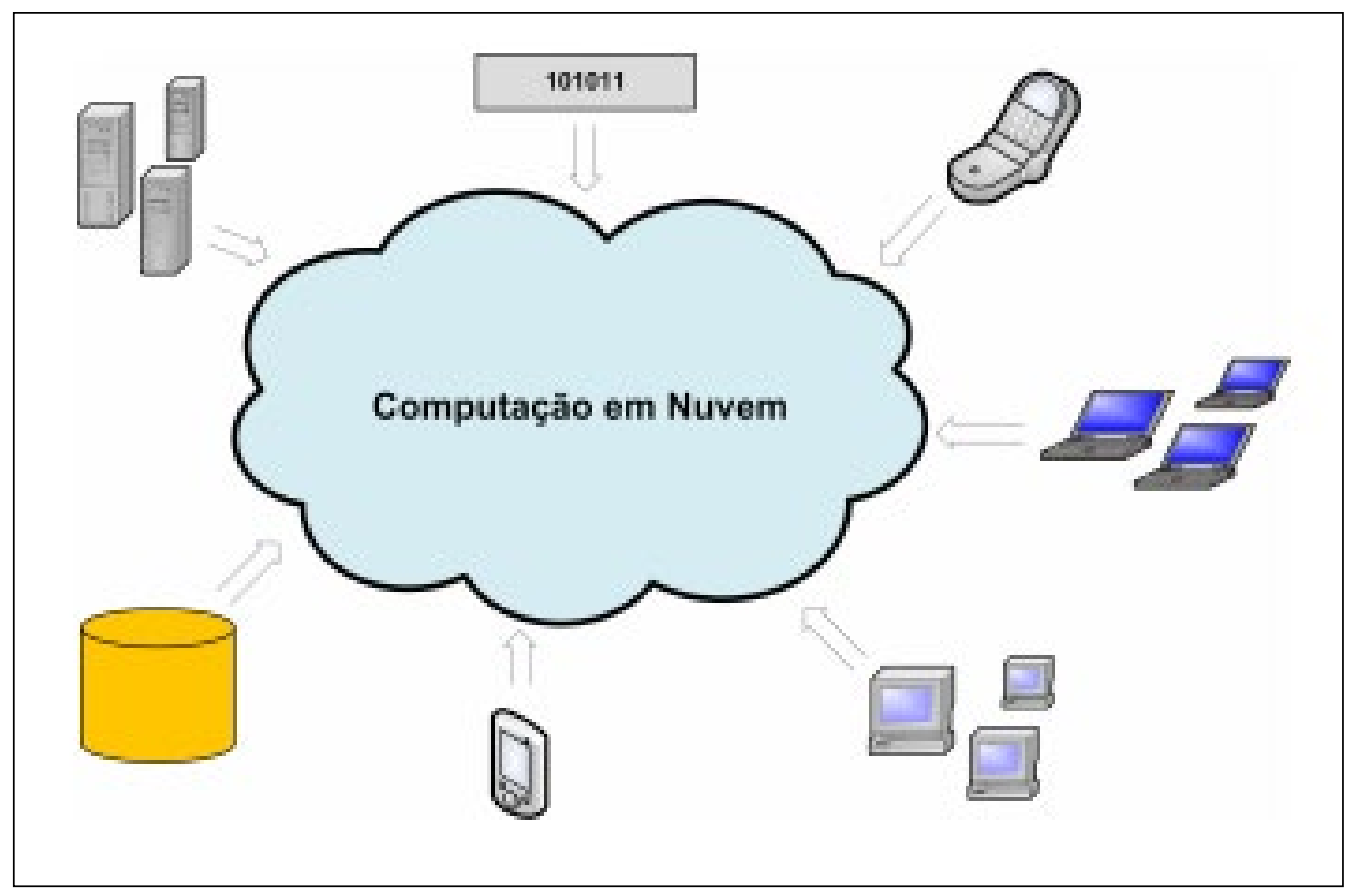

Fonte: Souza et al., (2009).

O avanço dessa tecnologia dá-se de forma muito dinâmica e não pode ser deixada de lado no meio acadêmico, onde a quantidade de recursos a serem fornecidos e mantidos pela TI só aumentam com o passar do tempo e com o surgimento de novas tecnologias.

Com a sua adoção, os professores podem desenvolver aulas cada vez mais dinâmicas, criando conteúdos mais ricos, customizados e compartilhar seus documentos de forma eletrônica, os quais podem ser acessados independentes do local, tornando o ensino mais desafiador e estimulante para os alunos. 
O estudo foi realizado com os docentes e discentes de uma instituição de ensino superior do vale do Taquari. Teve como foco a área da Tecnologia da Informação (TI), mais especificamente no tema computação em nuvem, cloud computing, onde procurou verificar qual a percepção dos docentes e discentes em relação ao uso da computação em nuvem na educação.

Este artigo visa trazer benefícios para o meio acadêmico, tanto para os docentes quanto para os discentes. Trazer conhecimento e esclarecimento referente à computação em nuvem, suas aplicações, conceitos, características, definições e consequências, sanar dúvidas e demonstrar como a tecnologia pode trazer benefícios para o aprendizado.

Os resultados alcançados pelo estudo poderão ser utilizados como base para uma melhor disseminação e aplicação da tecnologia, facilitando a compreensão do conceito e suas aplicações, identificando as principais dificuldades para serem sanadas por meio de treinamentos e palestras educativas, proporcionando um melhor uso da tecnologia no cotidiano das aulas.

\section{REFERENCIAL TEÓRICO}

Simplificadamente, cloud computing, se refere à ideia de utilizar, em qualquer lugar e independente de plataforma, as mais variadas aplicações por meio da internet com a mesma facilidade de tê-las instaladas em nossos próprios computadores (ALECRIM, 2015).

Para Alecrim (2015), com a evolução constante da tecnologia computacional e das telecomunicações, o acesso à internet vem se tornando cada vez mais amplo e rápido. Esse cenário está criando uma condição perfeita para a popularização do cloud computing.

Segundo Veras (2012), a arquitetura cloud computing significa mudar fundamentalmente a forma de operar a TI, saindo de um modelo baseado em aquisição de equipamentos para um modelo baseado em aquisição de serviços. A união do cloud computing com a virtualização, teoricamente permite obter o melhor dos mundos: otimização do uso dos recursos e flexibilidade para o usuário.

O elemento central do processamento e armazenamento dos dados e da informação na nuvem são os datacenters ${ }^{3}$. Assim, são centralizadas em grandes pontos de armazenamento e processamento, otimizando o uso dos recursos, nesses datacenters. A nuvem na verdade é um conjunto de grandes pontos de armazenamento e processamento de dados e informação (VERAS, 2012).

3 Datacenter, ou Centro de Processamento de Dados, é um ambiente projetado para concentrar servidores, equipamentos de processamento e armazenamento de dados e sistemas de ativos de rede, como switches, roteadores, e outros (COMSTOR, 2013). 
Para Veras (2012) a centralização em grandes estruturas, os datacenters, é viabilizada pela atual oferta de banda e pela existência de tecnologias que permitem alto poder de processamento e armazenamento em estruturas que reduzem o custo total de propriedade da infraestrutura de TI. Como se fossem aproveitados o melhor dos mundos, centralizam o processamento e armazenamento da informação em grandes estruturas que propiciam ganho de escala, ao mesmo tempo em que estão integradas em rede, permitindo obter flexibilidade. Por outro lado, essas estruturas demandam muita energia e constante refrigeração, tornando os projetos mais complexos.

Segundo Souza et al. (2009), o modelo de computação em nuvem foi desenvolvido com o objetivo de fornecer serviços de fácil acesso, baixo custo e com garantias de disponibilidade e escalabilidade. Fornece basicamente três benefícios:

- Reduzir o custo na aquisição e composição de toda infraestrutura requerida para atender às necessidades das empresas, podendo essa infraestrutura ser composta sob demanda e com recursos heterogêneos e de menor custo;

- Oferecer flexibilidade no que diz respeito à adição e substituição de recursos computacionais, podendo escalar tanto em nível de recurso em hardware quanto de software, dependendo do fim desejado;

- Promover uma facilidade e abstração de acesso aos usuários desses serviços, não sendo necessário um local específico para o acesso, assim trazendo mobilidade.

\subsection{Virtualização}

Para Chirigati (2009) a virtualização é um dos componentes chaves da computação em nuvem. Diz respeito à criação de ambientes virtuais, também conhecidos como máquinas virtuais (MV), a fim de abstrair as características de hardware. As MVs tem a capacidade de emular diversos sistemas operacionais em uma única plataforma computacional.

A virtualização permite que os ambientes virtuais possam ser ampliados ou reduzidos dinamicamente de maneira a atender a demanda momentânea. A escalabilidade está fortemente ligada a essa característica, seus recursos são facilmente escaláveis graças a esse dinamismo. As máquinas virtuais são definidas como interfaces de denominador comum entre os prestadores de infraestrutura e os desenvolvedores (ALMEIDA; MONÇÃO, 2010).

\subsection{Segurança}

Um dos maiores desafios da computação em nuvem é a segurança, pois disponibiliza seus serviços através da internet. Por utilizar recursos computacionais espalhados não se tem a localização exata de onde seus dados 
se encontram. Dessa forma, é preciso ter meios para impedir o acesso não autorizado a informações e que os dados permaneçam privados. A segurança deve ser considerada o fator determinante para prover a autenticidade, confidencialidade e integridade da computação em nuvem (SOUZA et al., 2009).

De acordo com Chees e Franklin (2013), a segurança para sistemas de informação se dividem em duas grandes categorias: proteger os ativos: hardware, software e infraestrutura de rede que formam sistema de TI; e proteger os dados: as informações contidas nos sistemas.

Conforme Carneiro e Ramos (2010), a segurança da informação pode ser definida como conjunto de medidas que se formam basicamente de controles e políticas de segurança, tendo como objetivo a proteção das informações, controlando o risco de revelação ou acesso por pessoas não autorizadas de um cliente ou empresa.

A Figura 2 apresenta os três princípios básicos da segurança da informação: confidencialidade, integridade e disponibilidade:

Figura 2 - Três princípios básicos da segurança da informação

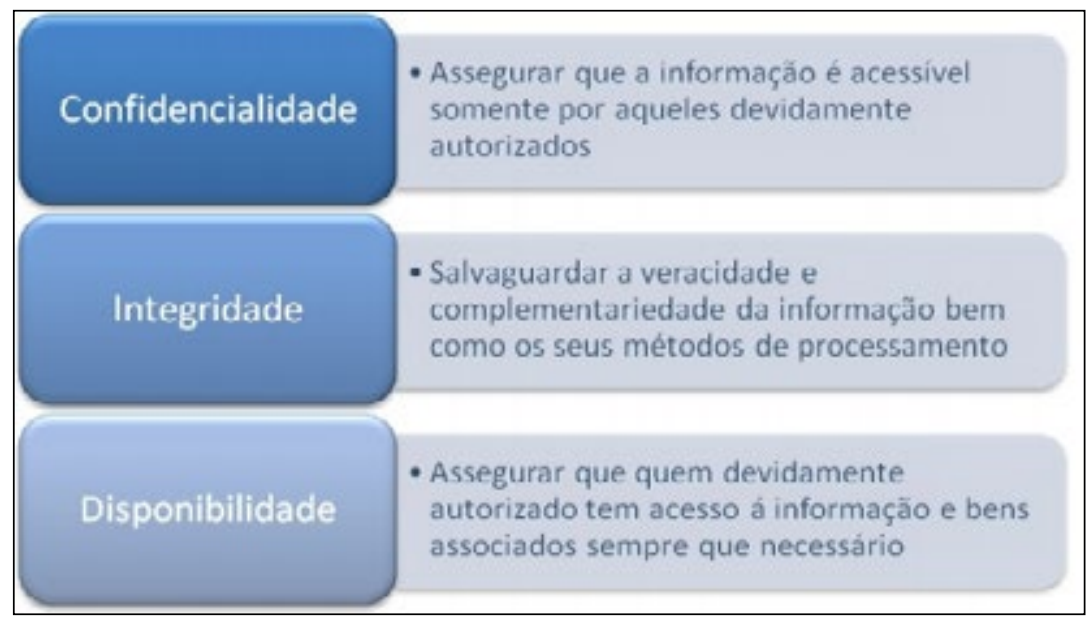

Fonte: Carneiro e Ramos (2010).

Para Castro e Souza (2010), é necessário buscar cada vez mais a adoção das melhores práticas em segurança, para que as organizações possam usufruir dos benefícios da computação em nuvem, uma vez que é difícil criar padrões para este modelo de serviço pelo seu alto nível de abstração.

\subsection{Aspectos econômicos}

Conforme Pedro (2011), os aspectos econômicos são a principal razão para a adoção da computação em nuvem, pois num primeiro momento a redução 
de custos e a automação da gestão de recursos se destacam nesta tecnologia. O ganho por meio desta redução de custo tem de ser cuidadosamente equilibrado com esforço de construir e executar um sistema desse tipo.

Em comparação com modelo de TI interno nas empresas, a computação nas nuvens consegue uma economia de $29 \%$. Em comparação com serviços terceirizados, a computação nas nuvens economiza $18 \%$ dos custos. É importante ressaltar que nestes dados não estão sendo consideradas questões como compra por capacidade e por uso, o que aumentaria os ganhos com a computação nas nuvens onde se paga pelo que é usado (PIGATTO, 2009).

\subsection{Características essenciais}

Em janeiro de 2011, o NIST (Nactional Institute of Standards and Tecnology) fez uma publicação na qual definiu a computação em nuvem em torno de suas cinco principais características, três modelos de serviço e quatro modelos de implantação. Conforme o NIST, computação em nuvem é o modelo que permite acesso à rede de forma onipresente, conveniente e sob demanda ao conjunto compartilhado de recursos de computação configuráveis, que podem ser rapidamente alocados e liberados, com o mínimo de esforço de gerenciamento ou interação com o provedor de serviço (VERAS, 2015).

Segundo o NIST, o modelo de computação em nuvem deve apresentar algumas características essenciais, que serão abordadas a seguir (VERAS, 2015).

\subsubsection{Autoatendimento sob demanda}

O usuário pode usufruir das funcionalidades computacionais sem a interação humana com os provedores de serviço. O hardware e o software dentro de uma nuvem podem ser reconfigurados automaticamente e estas modificações são apresentadas de forma transparente para os usuários, que possuem perfis diferentes e assim podem personalizar seus ambientes computacionais, de acordo com o privilégio de cada usuário (SOUZA et al., 2009).

\subsubsection{Amplo acesso a serviços de rede}

Recursos são disponibilizados através da internet e são acessados por via de mecanismos padronizados, podendo serem utilizados independentes da plataforma (VERAS, 2015).

\subsubsection{Pool de recursos}

Os recursos computacionais, físico ou virtual do provedor são utilizados para servir a múltiplos usuários, sendo alocados e realocados dinamicamente conforme a demanda (VERAS, 2015). 


\subsubsection{Elasticidade rápida}

As funcionalidades computacionais devem ser rápidas e elasticamente providas, assim como rapidamente liberadas. Os usuários dos recursos devem ter a impressão de que ele possui recursos ilimitados e de que pode-se adquirilos em qualquer quantidade e em qualquer momento (VERAS, 2015).

A virtualização auxilia a elasticidade rápida na computação em nuvem, criando várias instâncias de recursos requisitados utilizando um único recurso real (Aboulnaga et al., 2009 apud Souza et al., 2009). A virtualização torna possível abstrair características físicas de uma plataforma computacional, exibindo outro hardware virtual e emulando um ou mais ambientes, que podem ser independentes ou não (SOUZA et al., 2009).

\subsubsection{Serviços mensuráveis}

Os sistemas em nuvem automaticamente controlam e otimizam o uso de recurso por meio de uma capacidade de medição. A automação é realizada em algum nível de abstração apropriado para o tipo de serviço, tais como armazenamento, processamento, largura de banda e contas de usuários ativas (SOUZA et al., 2009).

\subsection{Modelos de implantação de computação em nuvem}

Quanto ao acesso aos ambientes de computação em nuvem têm-se diferentes tipos de implantação. A restrição ou abertura de acesso depende do processo de negócio, tipo de informação e nível de acesso desejado. Pelo desejo que certas empresas possuem de controlar o nível de acesso dos usuários a seus ambientes de computação em nuvem, surge a necessidade de ambientes mais restritos, onde somente usuários com autorização possam acessar (TAURION, 2009).

De acordo com a publicação do NIST, existem quatro principais modelos de implantação da cloud computing: nuvem pública, nuvem privada, nuvem híbrida e nuvens comunitárias, as quais serão abordadas a seguir (VERAS, 2015).

\subsubsection{Nuvens públicas}

São disponibilizadas publicamente através do modelo pague - por - uso. São oferecidas por organizações públicas ou por grandes grupos instrumentais que possuem grande capacidade de processamento e armazenamento (VERAS, 2012). 


\subsubsection{Nuvens privadas}

Taurion (2009), diz que nuvens privadas também podem ser chamadas de nuvens empresariais, correspondendo ao uso do conceito de servidores localizados internamente nas empresas gerenciadas pelas mesmas.

\subsubsection{Nuvens híbridas}

A sua infraestrutura é uma composição de duas ou mais nuvens, podendo ser, privadas, públicas ou comunitárias que continuam entidades únicas, porém conectadas através de tecnologias proprietárias ou padronizadas que proporcionam a portabilidade de dados e aplicações (VERAS, 2015).

\subsubsection{Nuvens comunitárias}

Conforme Veras (2015), esta infraestrutura da computação em nuvem é compartilhada por diversas organizações que possuem interesses comuns. A nuvem comunitária pode ser administrada por quem a compõe ou por terceiros, podendo existir tanto dentro como fora das organizações às quais pertencem.

\subsection{Modelos de Serviços na Computação em Nuvem}

A arquitetura de computação em nuvem pode ser dividida em três camadas básicas: a camada mais baixa é de infraestrutura como serviço (IaaS), a segunda camada é de plataforma como serviço (PaaS) e a última camada é de software como serviço (SaaS). Cada camada possui gerenciamento e monitoramento de forma independente (SOUZA et al., 2009).

A Figura 2 apresenta os atores dos modelos de acordo com os papéis desempenhados: 
Figura 2 - Papéis na computação em nuvem

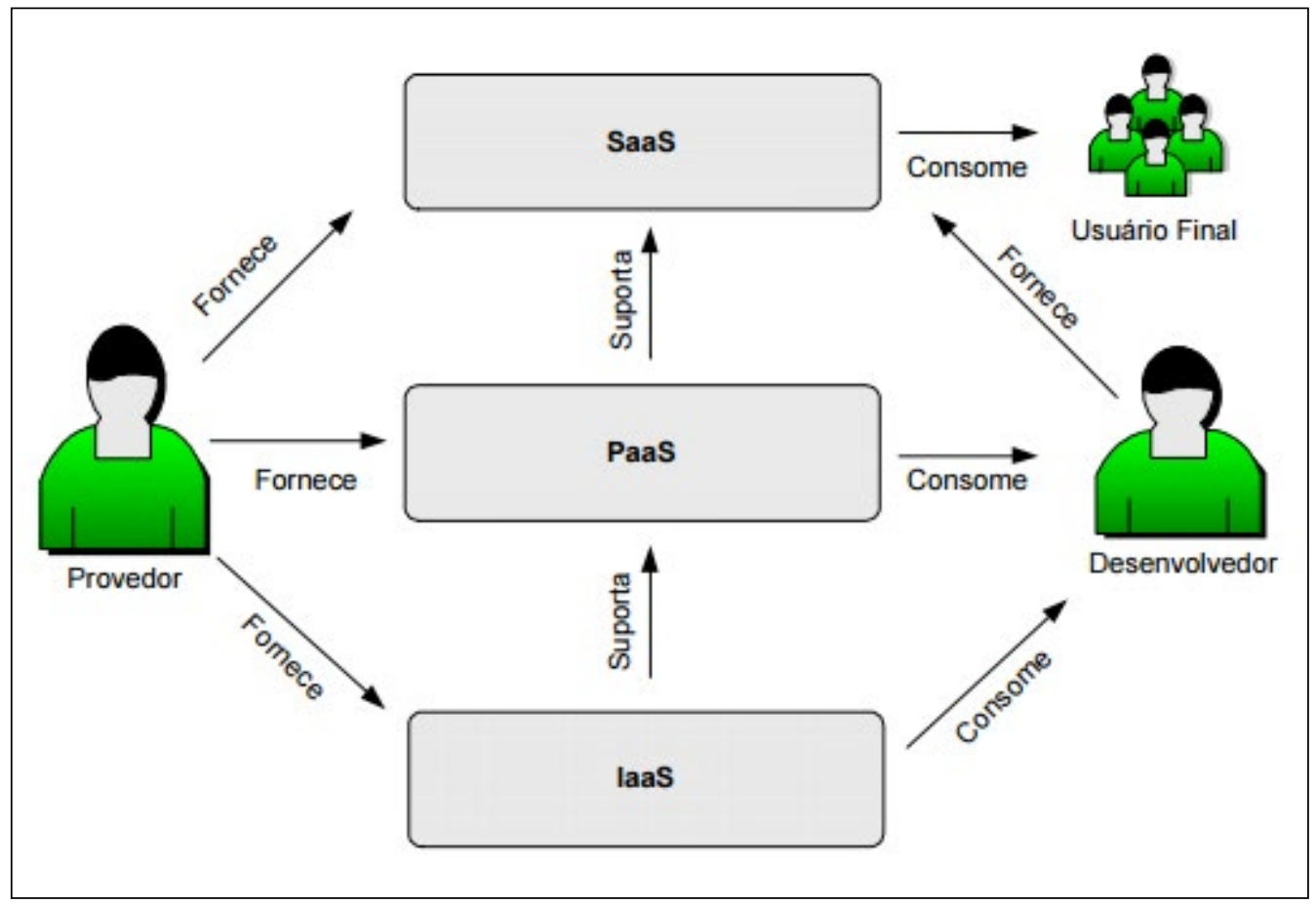

Fonte: Ruschel et al., (2008).

\subsubsection{Infraestrutura como serviço (IaaS)}

Conforme Veras (2012), infraestrutura como um Serviço (Infrastructure as a Service-IaaS): capacidade que o provedor tem de oferecer uma infraestrutura de processamento e armazenamento de forma transparente. $\mathrm{O}$ usuário não tem controle da infraestrutura física, mas, possui controle sobre sistemas operacionais, armazenamento, aplicações instaladas e controle limitado dos recursos de rede. AMAZON EC2 é um exemplo de IaaS.

\subsubsection{Plataforma como serviço (PaaS)}

Segundo Veras (2012), plataforma como um Serviço (Platform as a Service - PaaS): capacidade oferecida pelo provedor para o desenvolvedor de aplicações que serão executadas e disponibilizadas na nuvem. A plataforma na nuvem oferece um modelo de computação, armazenamento e comunicação para as aplicações. AZURE da Microsoft e AppEngine do Google são exemplos de PaaS. 


\subsubsection{Software como serviço (SaaS)}

Software como um Serviço (Software as a Service - SaaS): aplicações de interesse de uma grande quantidade de usuários passam a ser hospedadas na nuvem como uma alternativa ao processo local. As aplicações são oferecidas como serviços por provedores e acessadas pelos clientes por aplicações como o browser. Todo o controle e gerenciamento de rede, sistemas operacionais, servidores e armazenamento é feito pelo provedor de serviço. Exemplos de SaaS são: Google Apps e o SalesForce (VERAS, 2012).

\subsection{Utilização da computação em nuvem na educação}

No atual modelo educacional, o professor apresenta-se como uma figura central no processo de ensino, detentor de conhecimento e responsável por permiti-lo. Com as transformações ocorridas a partir da chegada dos computadores na educação, os educadores viram-se obrigados a adaptarem-se neste novo contexto. Por mais que o professor seja capacitado didaticamente, o conhecimento técnico, na maioria das vezes, torna-se barreira para introdução da informática na educação (BRAGA, 2011).

É muito importante que os educadores estejam preparados para a utilização dos novos recursos computacionais em suas aulas, sendo também importante que eles sejam conscientizados da importância da melhor utilização dos recursos de forma a extrair o melhor deles (BRAGA, 2011).

“A computação em nuvem pode auxiliar os professores não apenas no planejamento, mas também na organização, elaboração e avaliação de diversas atividades com os alunos" (BENNERTZ, 2011, texto digital).

\subsection{Vantagens}

Conforme Veras (2012), os possíveis benefícios do uso de um modelo de computação em nuvem para as organizações são:

- Menores custos de infraestrutura: elimina custos com capital e passa a pagar somente pelo uso;

- Aumento da utilização da infraestrutura: a infraestrutura compartilhada e sob demanda passa a ser mais utilizada e permite a redução do custo por parte do provedor;

- Aumento da segurança: uma infraestrutura centralizada pode melhorar a segurança incluindo rotinas de backup otimizadas e testadas;

- Acesso a aplicações sofisticadas: aplicações consideradas caras podem ser utilizadas no modelo sob demanda;

- Economia de energia: é possível, em uma estrutura centralizada, uma redução de custos de energia e refrigeração; 
- Aumento da produtividade por usuário: usuários podem utilizar as aplicações de qualquer lugar e isso impacta positivamente na produção;

- Aumento da confiabilidade: exigência de estrutura de contingência quase obrigatória em computação em nuvem;

- Escalabilidade sob demanda: permite alocar recursos sob demanda, tornando a escalabilidade uma realidade.

\subsection{Desvantagens}

Veras (2012) afirma que existem diversos desafios para a adoção da computação em nuvem, sendo esses os principais:

- Falta de interoperabilidade: a maioria dos modelos adotados pelos fornecedores de sistemas de computação em nuvem é integrada verticalmente e limita a escolha da plataforma;

- Compatibilidade entre aplicações: aplicações construídas para a computação em nuvem são muitas vezes incompatíveis com aplicações legadas;

- Dificuldades em obedecer a normas regulatórias: a regulação pode limitar o uso da computação em nuvem para alguns ambientes. Nuvens internas podem ser uma opção mais adequada para diversas organizações;

- Segurança inadequada: por compartilharem uma única infraestrutura e base de dados. As implantações individuais desses aplicativos ocupam partições virtuais, em vez de pilhas físicas separadas de hardware e software. Esta arquitetura, mesmo sendo interessante para diversas aplicações, pode trazer problemas com a segurança.

\section{METODOLOGIA UTILIZADA}

Quanto à sua natureza, é uma pesquisa básica, tem abordagem quantitativa e qualitativa, de caráter exploratório. Os principais procedimentos utilizados nesta pesquisa são: estudo de caso e survey ${ }^{4}$. A técnica de coleta de dados utilizada no trabalho foi a de um questionário estruturado, onde se procurou identificar o perfil dos docentes, o nível de conhecimento referente ao tema computação em nuvem, o domínio de uso da tecnologia, dificuldades e opiniões sobre a aplicação desta nova tecnologia na educação. As respostas

4 Pesquisas do tipo survey, ou levantamento, caracterizam-se pela interrogação direta das pessoas cujo comportamento se deseja conhecer. São solicitadas as informações a um grupo significativo de pessoas sobre o problema estudado, para em seguida serem obtidas as conclusões com base nos dados coletados (GIL, 2012). 
coletadas foram registradas em uma planilha, a fim de facilitar a análise dos dados.

O instrumento de coleta de dados utilizados foi um questionário estruturado, criado no Google Forms. De acordo com a resposta da última pergunta de cada seção, foi realizado o direcionamento para a seção correspondente, onde as questões foram criadas pelos autores com base na leitura de alguns artigos e trabalhos, com o intuito de obter as respostas dos objetivos propostos.

Dentre as limitações que poderiam ser encontradas, destacou-se o possível receio dos docentes em fornecer algumas informações, pois, nem todas as pessoas motivam-se da mesma forma para responder as questões solicitadas. Algumas poderiam até sentirem-se ameaçadas quando perguntadas sobre determinados assuntos. A principal limitação do questionário foi a baixa média de devoluções. Outro fator de limitação foi o grau de confiabilidade das respostas obtidas, pois nem sempre é possível confiar na veracidade de informações.

\section{ANÁLISE DOS DADOS}

O questionário destinado aos professores possuía 18 perguntas que foram divididas em cinco seções, onde a última pergunta de cada seção encaminhava o professor para a próxima seção, de acordo com a sua resposta.

As cinco seções foram divididas com o objetivo de descobrir as seguintes informações:

1. Dados pessoais do professor;

2. Nível de utilização e conhecimento;

3. Tipos de orientações recebidas;

4. Opinião sobre a computação em nuvem;

5. Interesse em novos serviços.

Esse questionário foi direcionado, através de e-mail, a 12 professores de uma instituição de ensino superior, que foram escolhidos de forma aleatória, optando-se por três professores de cada centro acadêmico, sendo que esta instituição possui quatro centros acadêmicos, sendo eles: CCBS (Centro de Ciências Biológicas e da Saúde), CCHS (Centro de Ciências Humanas e Sociais), CETEC (Centro de Ciências Exatas e Tecnológicas) e CGO (Centro de Gestão Organizacional).

O questionário destinado aos alunos possuía 12 perguntas que foram divididas em três seções, onde a última pergunta de cada seção encaminhava o aluno para a próxima seção, de acordo com a sua resposta.

As três seções foram divididas com o objetivo de descobrir as seguintes informações: 
1. Dados pessoais dos alunos;

2. Nível de utilização e conhecimento;

3. Uso da computação em nuvem nas aulas.

O questionário foi encaminhado, através de e-mail, para as turmas dos professores selecionados, obtendo assim 52 respostas.

\subsection{Respostas dos professores}

Dos 12 questionários encaminhados aos professores, oito foram respondidos. Verificou-se com esse conjunto de respostas que mesmo professores com mais tempo de docência estão abertos à utilização da computação em nuvem como ferramenta didática pedagógica. Inclusive, todos acreditam que a computação em nuvem tende a estar cada vez mais presente na educação, conforme o gráfico 1.

Gráfico 1 - Presença da computação em nuvem na educação

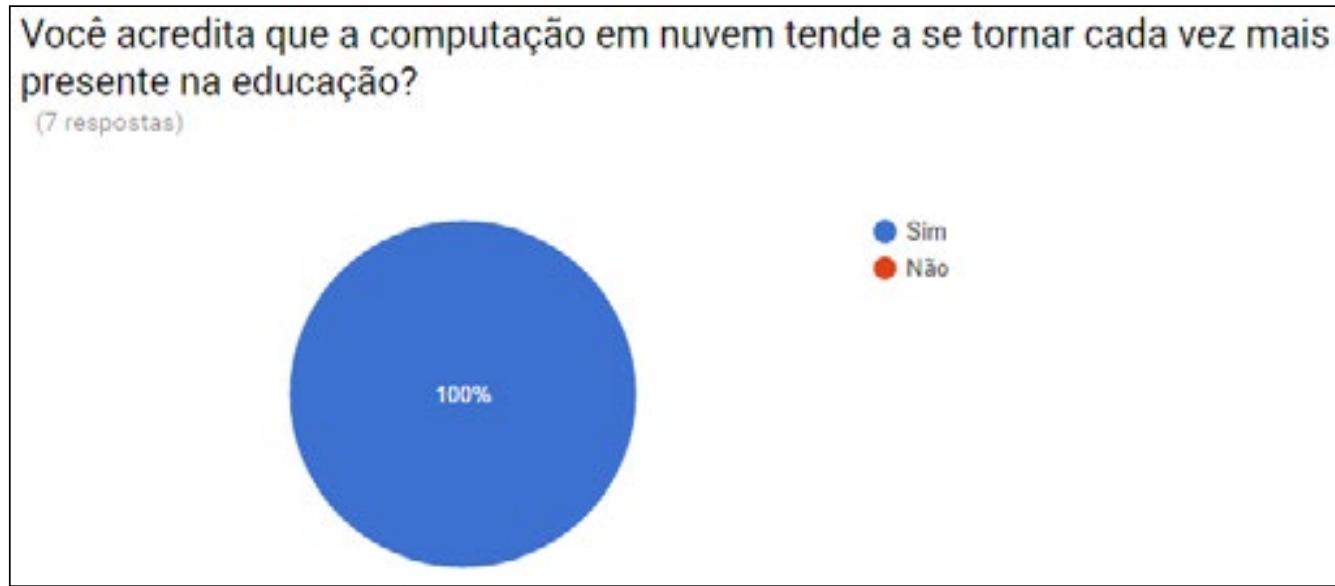

Fonte: Elaborado pelo autor com base nas respostas do questionário, 2016.

A maioria dos professores que responderam ao questionário possui um nível de conhecimento sobre o tema computação em nuvem muito boa. Já utilizam uma grande variedade de ferramentas, onde possuem um nível de satisfação alto, apesar de ainda existirem algumas limitações das ferramentas, $\mathrm{o}$ que acaba por diminuir a utilização total das mesmas.

Além disso, notou-se que, apesar da grande maioria dos professores terem recebido alguma orientação, a capacitação não deve ser interrompida. Devem ser desenvolvidas orientações de forma contínua, tanto por treinamentos como por fóruns, o que seria uma forma dinâmica e prática de continuar a desenvolver a cultura da utilização das ferramentas disponíveis. Os professores também se mostraram dispostos a aprender novas ferramentas 
para continuarem a se aperfeiçoar nas suas didáticas, tendo outros recursos, a partir dos quais novas metodologias podem ser empregadas em suas aulas.

\subsection{Respostas dos alunos}

O questionário enviado aos alunos obteve 52 retornos. Neste conjunto de respostas, pode-se verificar que, apesar dos alunos na sua grande maioria possuírem idade inferior a 33 anos, mais de $50 \%$ deles disseram não utilizar a computação em nuvem, sendo que, pelo menos metade deles, já está cursando o seu curso há mais de quatro anos, numa instituição que presa pela tecnologia e utiliza ferramentas de computação em nuvem desde os primeiros semestres.

Entre os que utilizam as ferramentas, $56 \%$ diz ter conhecimento das ferramentas, porém não as utilizam com frequência; somente $44 \%$ dos alunos acreditam conhecer bem as ferramentas e as utilizam com frequência, apesar de o nível de satisfação em relação aos serviços prestados seja classificado como regular, alto ou muito alto por $96 \%$ dos alunos que responderam ao questionário, conforme mostra o gráfico 2.

Gráfico 2 - Satisfação com os serviços utilizados

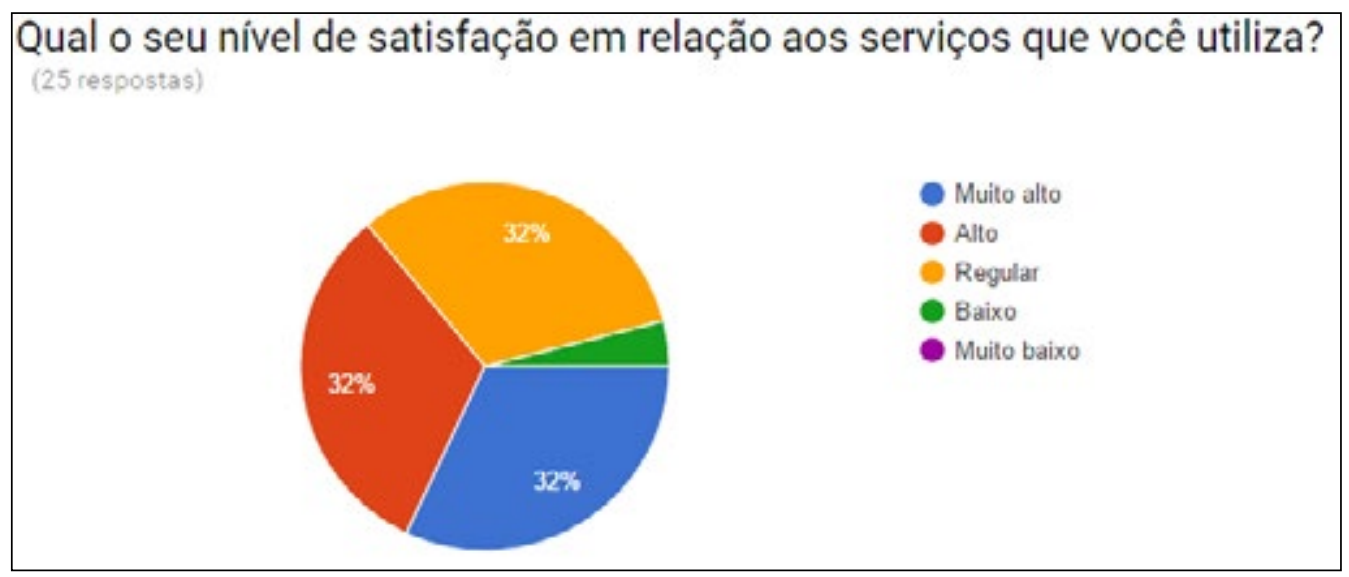

Fonte: Elaborado pelo autor com base nas respostas do questionário, 2016.

A principal vantagem citada foi a disponibilidade, a possibilidade de acessar os arquivos salvos em qualquer lugar a qualquer hora, junto com a flexibilidade e agilidade que essa disponibilidade traz. Em contra ponto veem a principal dificuldade que se trata da conexão ruim que infelizmente ainda é um problema de infraestrutura do nosso país.

Quanto ao uso da computação em nuvem na educação, pode-se observar que a grande maioria acredita que ela tende a se tornar cada vez mais presente e o seu uso já acontece para $48 \%$ dos alunos que responderam ao questionário. 
Dos alunos que já utilizam algum tipo de serviço hoje, 83,3\% acreditam que o uso desses serviços como recurso didático pedagógico auxilia na aprendizagem.

\section{CONSIDERAÇÕES FINAIS}

Este artigo teve por objetivo identificar qual é a percepção dos docentes e discentes em relação à utilização da computação em nuvem e como identificam que ela pode ser aplicada como ferramenta didática pedagógica.

Para isso, foram descritos alguns conceitos base para a adoção dessa nova tecnologia, que tem como princípio principal a disponibilidade e a agilidade com a ideia de utilizar em qualquer lugar e independente de plataforma, as mais variadas aplicações por meio da internet com a mesma facilidade de tê-las instaladas em computadores próprios. Esse conceito usado na educação tende a mudar o processo de ensino, oportunizando aulas mais dinâmicas e atraentes para as novas gerações. Para que isso aconteça, os docentes e discentes devem receber orientação para utilizarem melhor essa nova forma de didática.

Para poder identificar como está o conhecimento dos docentes e discentes a respeito da computação em nuvem, foram aplicados os questionários nos quais se percebeu que, tanto os docentes como os discentes acreditam que a computação em nuvem tende a ser cada vez mais presente na educação como uma nova ferramenta didática pedagógica. Ao serem perguntados sobre essa questão, 100\% dos docentes e $96 \%$ dos discentes responderam afirmativamente.

Outro fator que pode ser notado é que o nível de satisfação dos que dizem utilizar as ferramentas é alto, tanto por parte dos docentes como dos discentes. Ambos também dizem que a utilização da computação em nuvem como recurso didático pedagógico auxilia nas aulas.

Também se comprovou que há um grande número de discentes que não tem um bom conhecimento dessa nova tecnologia e ainda dizem não a utilizar. Isso ficou claro com a resposta de $51,9 \%$ dos discentes entrevistados que disseram não utilizar ferramentas disponibilizadas pela computação em nuvem.

Reforçando que, a principal limitação do questionário é a baixa média de devoluções. Outro fator de limitação é o grau de confiabilidade das respostas obtidas, pois nem sempre é possível confiar na veracidade de informações.

A grande preocupação deve estar na questão de disponibilizar continuamente, das mais variadas formas, explicações de como utilizar as ferramentas, tanto para os professores como para os alunos. Quanto mais conhecimento e mais informações forem transmitidas, mais facilmente as ferramentas serão usadas a pleno.

Há uma gama muito grande de ferramentas para serem usadas nas aulas, tornando-as mais atraentes, dinâmicas e desafiadoras para os novos 
alunos, aumentando seu interesse pelas mesmas, fugindo do modo tradicional de dar aula.

\title{
REFERÊNCIAS
}

\begin{abstract}
ALMEIDA, Dougrielle Barbosa; MONÇÃO, Leandro da Silva. Computação em Nuvem. 2010. 46 f. Monografia (Graduação) - Instituto Federal De Educação, Ciência E Tecnologia Fluminense Campus Campos - Centro. Curso Superior De Tecnologia Em Sistemas De Telecomunicações, Goytacazes, Rio de Janeiro, 2010. Disponível em: <http://bd.centro.iff.edu.br/xmlui/bitstream/handle/123456789/589/ Computa $\% \mathrm{C} 3 \% \mathrm{~A} 7 \% \mathrm{C} 3 \% \mathrm{~A} 3 \mathrm{o} \% 20 \mathrm{em} \% 20 \mathrm{Nuvem}$.pdf?sequence $=1 \&$ isAllowed $=\mathrm{y}>$ Acessado em: 29 abr. 2016.
\end{abstract}

ALECRIM, Emerson. O que é cloud computing (computação nas nuvens)?, 2015. Disponível em: <http:/ / www.infowester.com/cloudcomputing.php> Acessado em: 14 abr. 2016.

BENNERTZ, Rafael. 5 respostas para você começar a usar a computação em nuvem. Nova escola - Revista Abril, 2011. Disponível em: <http://revistaescola.abril.com. $\mathrm{br} /$ formacao/5-respostas-voce-comecar-usar-computacao-nuvem-645948.shtml> Acessado em: 04 mai. 2016.

BRAGA, Juliana Vasconcelos. Informática na educação - ferramenta de apoio ao ensino e de estruturação do profissional do futuro. 2011. Disponível em: <http:/ / www.anapolis.go.gov.br/revistaanapolisdigital/wp-content/uploads/2011/04/ informatica-na-educacao-ferramenta-de-apoio-ao-ensino-e-de-estruturacao-doprofissional-do-futuro.pdf> Acessado em: 04 mai. 2016.

CASTRO, Rita. C. C. de; SOUSA, Verônica. L. Pimental de. Segurança em Cloud Computing: Governança e Gerenciamento de Riscos de Segurança, 2010. Disponível em: <http:/ / www.infobrasil.inf.br/userfiles/26-05-S5-1-68740-Seguranca\%20em\%20 Cloud.pdf> Acesso em 04 mai. 2016.

CARNEIRO, Ricardo J. G.; RAMOS, Cleisson C. L. de. A Segurança Na Preservação E Uso Das Informações Na Computação Nas Nuvens, 2010. Disponível em: <https:/ / ricardojgc.files.wordpress.com/2010/10/artigo-computacao-nas-nuvens.pdf> Acessado em 06 mai. 2016.

CHEES, Brian J. S.; FRANKLIN Jr., Curtis. Cloud Computing - Computação em Nuvem - Tecnologias e Estratégias Ubíquo. São Paulo: M.Books do Brasil Editora Ltda., 2013.

CHIRIGATI, Fernando Seabra. Computação em Nuvem. Universidade Federal do Rio de Janeiro. 2009. Disponível em: <http:/ / www.gta.ufrj.br/ensino/eel879/trabalhos_ vf_2009_2/seabra/index.html> Acessado em 26 abr. 2016. 
COMSTOR, Canal. O QUE É UM DATA CENTER? Canal Comstor - O blog dos negócios de TI. 2013. Disponível em: <http://blogbrasil.comstor.com/bid/334188/Oque-um-Data-Center> Acessado em 13 dez. 2016

PEDRO, Paulo César Silva. Cloud Computing: Estudo do Impacto nas Organizações. 2011. 138 f. Tese (Mestrado) - Escola Superior de Tecnologia e Gestão de Viseu. Curso de Sistemas e Tecnologias de Informação para as Organizações, Viseu, 2011. Disponível em: <http:/ / repositorio.ipv.pt/bitstream/10400.19/1125/1/Projecto_e_ disserta\%C3\%A7\%C3\%A3o_paulo_pedro_7945.pdf> Acessado em: 23 abr. 2016.

PIGATTO, Daniel Fernando. Estudo e Implementação de uma Solução de Softwares Aplicativos Utilizando Computação nas Nuvens. 2009. 102 f. Trabalho de Conclusão de Curso (Graduação) - Universidade Regional Integrada do Alto Uruguai e das Missões - Campus de Erechim. Curso de Ciência da Computação, Erechim, 2009. Disponível em: <http:/ / pt.slideshare.net/dhannyel/trabalho-de-concluso-de-cursode-graduao> Acessado em: 19 abr. 2016.

RUSCHEL, Henrique; ZANOTTO, Mariana Susan; MOTA, Wélton Costa da. Computação em Nuvem. 2008. 15 f. Artigo (Especialização em Redes e Segurança de Sistemas) - Pontifícia Universidade Católica do Paraná, Curitiba, 2010. Disponível em: <http://www.ppgia.pucpr.br/ jamhour/RSS/TCCRSS08B/Welton \%20Costa $\% 20$ da\%20Mota\%20-\%20Artigo.pdf> Acessado em: 03 mai. 2016.

TAURION, Cezar. Cloud Computing: computação em nuvem: transformando o mundo da tecnologia da informação. Rio de Janeiro: Brasport, 2009.

VERAS, Manoel. Virtualização: componente central do Datacenter. Rio de Janeiro: Brasport, 2012.

VERAS, Manoel. Virtualização: tecnologia central do Datacenter. $2^{\mathrm{a}}$ ed. Rio de Janeiro: Brasport, 2015. 